\title{
HLB Concept: A Way to Never Forget It
}

\author{
E Sócrates T Egito*1,2, Lucas Amaral Machado ${ }^{1}$, Iury EG Farias ${ }^{1}$, K Gyselle H Silva ${ }^{2}$ and Anselmo G Oliveira ${ }^{3}$ \\ ${ }^{1}$ Graduate Program in Health Sciences, Brazil \\ ${ }^{2}$ Laboratory of hybrid systems, Brazil
}

${ }^{3}$ Department of Drugs and Medicines, Faculty of Pharmaceutical Sciences, Brazil

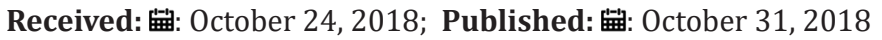

*Corresponding author: E Sócrates T Egito, Rua Praia de Areia Branca, 894859094-450 - Natal/RN Brazil

\begin{abstract}
This mini-review discusses the physicochemical parameters related to the formation of emulsified systems and the role of surfactants on this process. To this regard, several considerations about the chemical properties of surfactants (such as hydrophobicity and lipophilicity) and their hydrophilic-lipophilic balance (HLB) were discussed. The main idea of this expert opinion is to show that surfactants with high HLB value are predominantly hydrophilic, whereas low HLB scores indicate the lipophilic net of the surfactants. Thus, based on the most relevant aspects, a simple and easy way to understand the HLB concept is suggested.
\end{abstract}

\section{Text Body}

Emulsions are dispersed systems made of the mixture of two immiscible liquid phases stabilized by surfactants. They have been used in several areas (specially in the food and pharmaceutical industries) due to their advantages, such as the ability to deliver drug molecules (commonly lipophilic drugs) as well as to improve organoleptic and biopharmaceutical characteristics of drugs and other bioactive compounds [1,2]. Although several theories have been hypothesized to explain the chemical and physicochemical mechanisms and interactions involved in their formation, no universal emulsification theory has been reported [2]. Furthermore, different types of emulsifying agents can be used in emulsions to improve their stability according to several physicochemical principles [3]. However, despite the knowledge about the organization of oil droplets and surfactants in the emulsified systems and considering the mechanisms involved on the interfacial tension decrease, several emulsification theories are reported, which makes it difficult for a scientific agreement about the overall phenomena involved in the emulsion formation [2].

In this context, the interfacial tension can be understand as the resistance of immiscible liquids in mixing themselves with one another, preventing one to self-disperse in another in the form of droplets. Moreover, surfactants are amphiphilic molecules that can be used to reduce the interfacial tension, enabling the dispersion of such liquids in themselves in the form of droplets, providing a physicochemical stability to the emulsion and reducing the occurrence of instability phenomena such as the flocculation and coalescence of droplets [4]. Concerning the physicochemical characteristics and chemical composition of the emulsions, these dispersed systems stand out as an important technological strategy on the development of new medicines in the biomedical area, allowing the improvement of drug bioavailability and the decrease of their side effects. However, due to the immiscibility of the oily and aqueous phases, the correct choice of surfactants remains as a critical step in the emulsion development [5-7].

Indeed, the knowledge about hydrophilic-lipophilic balance (HLB) is an essential parameter related to the emulsion production because it allows the selection of a suitable surfactant or even a surfactant blend required to produce a stable emulsified system. Historically, the HLB concept proposed by Griffin in 1949 showed itself as one of the most important tools to develop and stabilize emulsified systems [4,8], especially when before 1950, the surfactant choice was carried out empirically, through trial-anderror steps. In fact, Griffin's HLB System was an attempt to systemize the choice of a suitable surfactant, and as a result, the methodology to prepare stable emulsions became more rational [4]. In Griffin's theory, surfactants and oily phases are classified in terms of HLB values required for an emulsification process, which would produce a stable emulsified system [6,7]. Thus, each surfactant presents one intrinsic number, its HLB value, which represents its hydrophiliclipophilic inherent property, which can range from 1 up to 40 [6,7].

Accordingly, 10 is the key number that divides the lipophilicity and hydrophobicity character of each surfactant. Therefore, 
surfactants with HLB value between 1 and 10 are considered lipophilic and the ones with HLB ranging between 10 and 40 are considered hydrophilic. In addition, the use of a blend of two or more surfactants with different HLB values is a common practice required to prepare more stable emulsified systems $[6,7,9,10]$. Indeed, based on Griffin's HLB concept, a mixture of immiscible liquids (such as oil and water) will only result in a stable emulsion with fluidity and milky characteristics if a surfactant or a blend of surfactants HLB value reaches an optimal score, which is called critical HLB (cHLB) and depends on the physicochemical properties of the oily phase [6-8]. By way of explanation, the surfactant's HLB scores and the cHLB of the oily phase of the emulsions are highly correlated, since only surfactant systems with HLB values approximate to the oily phase cHLB are able to be located at the oil-in-water interface of the emulsified systems and, by reaching this requirement, they allow the formation of a metastable emulsion [4].

On the other hand, a surfactant or a blend at lower or higher HLB scores than the oil cHLB will be dispersed in one of the emulsion phases rather than at the interface, allowing, at the first moment, the production of a system with a milky aspect, but with poor physicochemical stability and high susceptibility to instability phenomena. Currently, other parameters, such as zeta potential, droplet size, presence of physical stabilizers (responsible for increasing viscosity), temperature, surfactant concentration and the surfactant electrical charge have been described and widely studied in the emulsion stabilization process, showing that although highly relevant, the HLB and cHLB are not the only parameters involved in this process. However, the correct use of the HLB and CHLB parameters reduces time of preformulation and the amount of pharmaceutical excipients once further stabilization adjustments might be unnecessary. Thus, it is important to highlight that HLB and CHLB are still the first and most common parameters to be studied on the development of emulsified systems, allowing the obtaining of stable formulations suitable for manufacturing by pharmaceutical companies.

\section{References}

1. Amaral Machado L, Xavier Junior FH, Rutckeviski R, Morais AR, Alencar EN, et al. (2016) New Trends on Antineoplastic Therapy Research: Bullfrog (Rana catesbeiana Shaw) Oil Nanostructured Systems. Molecules 21(5).

2. Morais ARV, Alencar EN, Xavier Junior FH, Oliveira CM, Marcelino HR, et al. (2016) Freeze-drying of emulsified systems: A review. Int J Pharm 503(1-2): 102-114.

3. Alfred N Martin, Pilar Bustamante, Chun AHC (1993) Physical Pharmacy: Physical Chemical Principles in the Pharmaceutical Sciences ( $4^{\text {th }}$ Edn.). Lippincott Williams \& Wilkins pp. 622.

4. Griffin WC (1949) Classification of surface-active agents by" HLB". J Soc Cos Chemists 1(5): 311-326.

5. Lieberman HA, Rieger MM, Banker G (1988) Pharmaceutical dosage forms-disperse systems. New York: Dekker M (Eds.) p. 49-90; 210-12; 85-366.

6. Becher P (1983) Encyclopedia of emulsion technology. Dekker M (Eds.) New York, USA, pp. 744.

7. Krishna G, Wood GC, Sheth BB (1998) Improving emulsification efficacy of lecithin by formulation design I: Effect of adding a secondary surfactant. PDA J Pharm Sci Technol 52(6): 331-336.

8. Griffin WC (1954) Calculation of HLB value of non-ionic surfactants. J Soc Cos Chemists 5: 249-256.

9. Macedo JPF, Fernandes LL, Formiga FR, Reis MF, Nagashima T, et al. (2006) Micro-emultocrit technique: A valuable tool for determination of critical HLB value of emulsions. Aaps Pharmscitech 7(1).

10. Prinderre P, Piccerelle P, Cauture E, Kalantzis G, Reynier JP, et al. (1998) Formulation and evaluation of $\mathrm{o} / \mathrm{w}$ emulsions using experimental design. Int J Pharm 163(1-2): 73-79.

\section{ISSN: 2574-1241}

\section{DOI: $10.26717 / B J S T R .2018 .10 .001983$}

E Sócrates T Egito. Biomed J Sci \& Tech Res

This work is licensed under Creative

Commons Attribution 4.0 License

Submission Link: https://biomedres.us/submit-manuscript.php

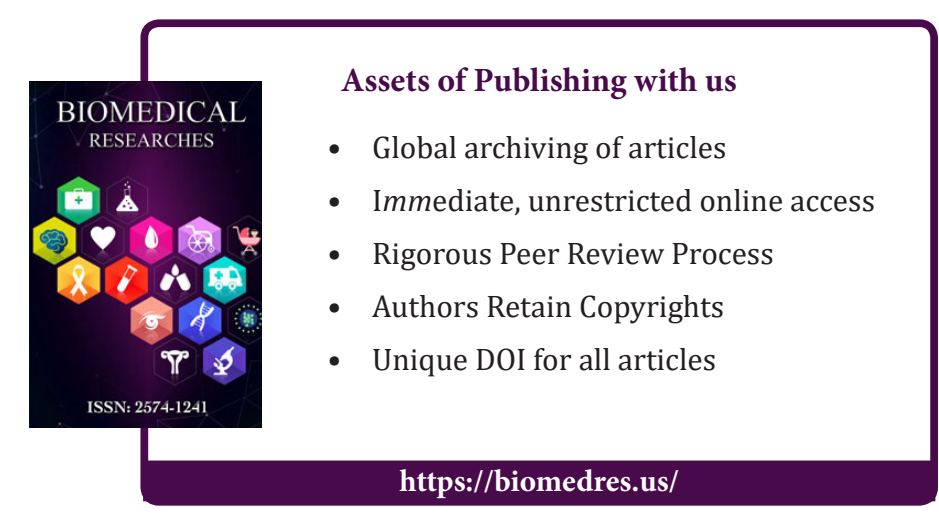

